\title{
Atuação do Fisioterapeuta na inclusão de crianças especiais nas escolas: uma revisão da literatura
}

Physiotherapist's performance in the inclusion of special children in schools: a review of the literature

Resumo: O presente estudo tem como objetivo mostrar os aspectos da inclusão escolar de crianças especiais e como o fisioterapeuta pode atuar de forma efetiva na elaboração de estratégias para o aprendizado. Crianças especiais são crianças que apresentam prejuízos motores, comportamentais e de aprendizado. A Declaração de Salamanca, aprovada na Conferência Mundial de Educação Especial em 1994, passou a se considerar a inclusão dos alunos com necessidades educativas especiais em classes regulares como a forma mais avançada de democratização das oportunidades educacionais. Neste contexto de educação especial o papel do fisioterapeuta é minimizaras dificuldades físicas das crianças especiais.

Palavras chave: educação, escola, crianças especiais, deficiência física, fisioterapeuta.

Abstract: This study aims to show the aspects of school inclusion of special children and how the physical therapist can act effectively in the development of learning strategies. Special children are children with motor, behavioral and learning impairments. The Declaration of Salamanca, adopted at the World Conference on Special Education in 1994, has considered the inclusion of students with special educational needs into regular classes as the most advanced form of democratization of educational opportunities. In this context of special education the role of the physiotherapist is to minimize the physical difficulties of special children.

Keywords: education, school, special children, physical disability, physiotherapist.

'Mestranda em Ciências da Educação pela FISC, Graduada em Fisioterapia pelo Centro Universitário do Leste de Minas Gerais, Especialista em Fisioterapia na Saúde Mulher pela Faculdade Ciências Médica - MG, mirlenesamora@hotmail.com.

$\stackrel{2}{2}$ Mestranda em Ciências da Educação pela FISC, Licenciatura em Matemática e Física pela UniBH, patriciahelenadutra@gmail.com. 


\section{INTRODUÇÃO}

Crianças especiais são crianças que apresentam prejuízos

motores, comportamentais e de aprendizado, que limitam sua participação social e seu desempenho funcional, tornando-as pouco funcionais e dependentes de cuidados específicos (BECKUNG e HAGBERG, 2002; FARIAS e BUCHALLA, 2005).

A Lei de Diretrizes e Bases da Educação Nacional, Lei no 9.394/96, no artigo 59, recomenda que os sistemas de ensino devam garantir aos estudantes, métodos, recursos e organização específica para atender às suas necessidades e assegura a terminalidade específica àqueles que não atingiram o nível exigido para a conclusão do ensino fundamental em virtude de sua deficiência.

A Declaração de Salamanca, aprovada na Conferência Mundial de Educação Especial em 1994, passou a se considerar a inclusão dos alunos com necessidades educativas especiais em classes regulares como a forma mais avançada de democratização das oportunidades educacionais.

Conforme De Carlo e Bartalotti (2001), não basta propiciar ao sujeito situações de interação, o que significaria apenas sua inserção no sistema escolar. Para os autores a relação educativa é fundada a partir de medidas planejadas pelo professor que possibilite a aprendizagem. Para garantir a efetividade da relação de ensino aprendizagem é preciso conhecer o caminho percorrido por aquele indivíduo, cultura, meio social e experiências vivenciadas.

De acordo com Maciel (2000), é de suma importante que os professores estejam cientes do diagnóstico e prognóstico do aluno com necessidades educativas especiais, conversar com pais ou responsáveis para conhecer todo o histórico de vida desse aluno, a fim de traçar estratégias conjuntas de estimulação entre família e escola, peçam orientações e procurem profissionais como psicólogos, fisioterapeutas, fonoaudiólogos que estejam atendendo ou que já atenderam esses alunos, solicitando relatórios e avaliações, pesquisem técnicas, métodos e estratégias de ensino, em que variáveis como o desenvolvimento da linguagem, o desenvolvimento físico e, sobre tudo as experiências sociais estejam presentes.

Segundo Aubert (2002), o fisioterapeuta pode ser um profissional valioso para a comunidade escolar, ao fazer sugestões de equipamentos que possam melhorar a experiência educacional da criança com deficiência física. A integração entre o professor e o fisioterapeuta é considerada por Sellers (1980) indispensável, pois a maioria dos professores não possuem treinamento e experiência para trabalhar com alunos com deficiência física, dificultando o entendimento do desempenho motor do aluno, e desta forma interferindo na sua atuação no sentido de encontrar a melhor forma de auxiliar esse aluno durante a realização de atividades escolares.

\section{MÉTODO}

Foi realizado um estudo de revisão sistemática da literatura baseada em pesquisas nacionais e internacionais, publicados entre os anos de 2000 e 2017 nas bases de dados Scielo, Lilacs, Medline, Pubmed e junto as bases de universidades. As palavras chave utilizadas foram: educação, escola, crianças especiais, deficiência física, fisioterapeuta. 
Foram incluídos nesta revisão os artigos mais relevantes considerados pelo autor. Foram excluídos os estudos que não apresentavam qualidade metodológica ou não abordavam diretamente o tema.

\section{RESULTADOS}

Foram encontrados 10 artigos publicados que referissem as palavras chaves, os mesmos foram descritos na tabela 1 e utilizados na discussão do presente estudo.

Tabela 1

AUTOR E ANO

\begin{tabular}{ll}
\hline & $\begin{array}{l}\text { Avaliação e participação do } \\
\text { fisioterapeuta na prescrição } \\
\text { do mobiliário escolar } \\
\text { Satilizado por alunos com } \\
\text { paralisia cerebral em } \\
\text { escolas estaduais públicas } \\
\text { da rede regular de ensino. }\end{array}$
\end{tabular}

Batista (2005)
O processo de inclusão do deficiente físico no ensino regular das escolas municipais do perímetro urbano de Tubarão.
Os alunos com deficiência física necessitam de modificações no ambiente escolar que podem envolver a adequação do espaço físico, de material escolar, de recursos pedagógicos, equipamentos e mobiliário escolar específico, bem como de recursos humanos capacitados para atuar junto a este aluno.
Estudo realizado em oito escolas observou-se que $73 \%$ professores não possuem conhecimento a cerca das deficiências físicas, $90 \%$ dos docentes não possuem conhecimento sobre a patologia dos alunos e $93 \%$ das salas de aula não existem deficientes físicos. O mais preocupante, é que $100 \%$ dos professores não tem formação para lidar com o deficiente físico.
O fisioterapeuta deve intervir e auxiliar no processo de inclusão, por meio de ações como educação em saúde para funcionários da escola, pais e alunos, eliminação de barreiras arquitetônicas e melhora da acessibilidade, adaptações de materiais e mobiliário, bem como habilitar as pessoas com deficiência através movimentos e posturas favoráveis à realização das tarefas escolares.
A atuação do fisioterapeuta na inclusão de crianças deficientes físicas em escolas regulares.
Importância da inclusão

Silva e Mazzotta (2002) escolar na reabilitação fisioterapêutica de crianças com paralisia cerebral.
Cabe ao fisioterapeuta identificar as barreiras que a criança enfrenta no ambiente escolar, bem como as expectativas e as exigências para ela poder interagir nesse ambiente, além de identificar as demandas que a criança enfrenta em relação ao seu enduro, sua mobilidade, força e destreza.

O Fisioterapeuta tem papel preponderante no Análise da acessibilidade dos ambiente escolar uma vez que poderá propor mudanças e inovações não somente externa como internamente, possibilitando melhores condições de acesso e permanência do portador de deficiência física proporcionando assim sua inclusão no ambiente escolar e melhorar na qualidade de vida. 
O cuidar do aluno com deficiência física na educação

Melo e Ferreira (2009) infantil sob a ótica das professoras.

Contribuição de um programa de jogos e brincadeiras adaptados para a estimulação de habilidades motoras em alunos com deficiência física.
É preciso que o profissional fisioterapeuta perceba que a instituição educacional é um espaço de aprendizagem e que suas orientações na equipe escolar têm como objetivo possibilitar a criança com deficiência física o desenvolvimento máximo de sua funcionalidade, estimulando-a desenvolver todas suas potencialidades com segurança e participação ativa no espaço escolar.

O fisioterapeuta junto aos professores pode por meio de brincadeiras adaptadas, como gincanas, mímica, boliche, arremesso na cesta de basquete, jogos com bola, xadrez, jogos de quebra-cabeça, jogos de peças e de memória, alongamentos, relaxamentos, entre outras, estimular o desenvolvimento da criança deficiente física.

O fisioterapeuta no ambiente escolar é indispensável, pois ele oferece às crianças com deficiência estímulos para um melhor desenvolvimento neuropsicomotor, aprimorando suas habilidades indispensáveis ao processo de alfabetização, dentre eles pode-se citar coordenação motora fina, equilíbrio, propriocepção e força muscular.
Niehues e Niehues (2014)

\section{Educação Inclusiva de Crianças com Deficiência Física: Importância da Fisioterapia no Ambiente Escolar.}

Estudo realizado com 47 fisioterapeutas revelou que apesar de conhecida a importância da atuação do profissional no contexto escolar, a maioria dos profissionais pesquisados não participam das ações voltadas para melhorar o aprendizado e a inclusão dos alunos com deficiência física, embora lidem diretamente com crianças e adolescentes com essas condições em sua prática clínica.
Santos, Lara e Folmer (2015)
Atuação de fisioterapeutas na

Melo, Lucena e Saraiva (2017) deficiência física no ensino regular.
Inclusão escolar: possíveis contribuições da fisioterapia sob a óptica de professoras.
Ressaltam que há a necessidade de o profissional fisioterapeuta reconhecer e conhecer que o ambiente escolar é também um dos seus espaços de atuação, para que possa disseminar conhecimento, inicialmente, para a comunidade universitária. 


\section{DISCUSSÃO}

A educação no nosso país por muitos anos foi segregativa e até mesmo exclusiva. Mas a partir da década de 80 , muitas críticas surgiram em relação a este sistema e debates surgiram em torno da Educação Inclusiva. Os deficientes deixaram de ser isolados e passaram a ter direito à vida digna, abandonando as instituições para deficientes. As crianças e jovens conseguiram o direito de estudar em escolas regulares, frequentando as mesmas instituições e turmas de crianças não deficientes (OMOTE, 1999).

Deste modo, os alunos com deficiência física necessitam de modificações no ambiente escolar que podem envolver a adequação do espaço físico, de material escolar, de recursos pedagógicos, equipamentos e mobiliário escolar específico, além de recursos humanos capacitados para atuar junto a este aluno, possibilitando oportunidades iguais e um desempenho satisfatório nas atividades desenvolvidas nesse meio (SARAIVA e MELO 2011).

Estudo realizado por Batista (2005), em oito escolas, observou-se que $73 \%$ professores não possuem conhecimento a cerca das deficiências físicas, $90 \%$ dos docentes não possuem conhecimento sobre a patologia dos alunos e $93 \%$ das salas de aula não existem deficientes físicos. O mais alarmante, é que $100 \%$ dos professores não tem formação para lidar com o deficiente físico.

Durce et al., (2006), afirmam que o fisioterapeuta deve intervir e auxiliar no processo de inclusão, por meio de ações como educação em saúde para funcionários da escola, pais e alunos, eliminação de barreiras arquitetônicas, melhora da acessibilidade, adaptações de materiais e mobiliário, bem como habilitar as pessoas com deficiência através movimentos e posturas favoráveis à realização das tarefas escolares.

Segundo Silva e Mazzotta (2002), cabe ao fisioterapeuta identificar as barreiras que a criança enfrenta no ambiente escolar, bem como as expectativas e as exigências para a mesma possa interagir nesse ambiente. profissional também cumpre identificar as demandas que a criança enfrenta em relação ao seu enduro, sua mobilidade, força e destreza.

O Fisioterapeuta tem papel preponderante no ambiente escolar uma vez que poderá propor mudanças e inovações não somente externa como internamente, possibilitando melhores condições de acesso e permanência do portador de deficiência física , favorecendo assim sua inclusão no ambiente escolar e melhora da qualidade de vida (TAGLIARI, TRÊS e OLIVEIRA 2006).

Para tanto, é preciso que o profissional fisioterapeuta perceba que a instituição educacional é um espaço de aprendizagem e que suas orientações na equipe escolar tem como objetivo permitir a criança com deficiência física o desenvolvimento máximo de sua funcionalidade, estimulando-a desenvolver todas suas potencialidades com segurança e participação no espaço escolar (MELO e FERREIRA, 2009).

O fisioterapeuta junto aos professores pode por meio de brincadeiras adaptadas, como gincanas, mímica, boliche, arremesso na cesta de basquete, jogos com bola, xadrez, jogos de quebra-cabeça, jogos de peças e de memória, alongamentos, relaxamentos, entre 
outras, estimular o desenvolvimento da criança deficiente física. Por meio destas, estimular na criança a sensibilidade epicrítica e tátil, discriminação de textura, peso, tamanho, desenvolve-se habilidades motora (agarrar, manusear, jogar), ou seja, trabalhar tanto motricidade fina quanto a ampla. BRACCIALLI, MANZINI e REGANHAN, 2004).

O fisioterapeuta no ambiente escolar é indispensável, pois ele oferece às crianças com deficiência estímulos para um melhor desenvolvimento neuropsicomotor, aprimorando suas habilidades indispensáveis ao processo de alfabetização, dentre eles pode-se citar coordenação motora fina, equilíbrio, propriocepção, e força muscular (NIEHUES e NIEHUES 2014).

Em contrapartida um estudo realizado com 47 fisioterapeutas revelou que apesar de conhecida a importância da atuação do profissional no contexto escolar, a maioria dos profissionais pesquisados não participam das ações voltadas para melhorar o aprendizado e a inclusão dos alunos com deficiência física, embora lidem diretamente com crianças e adolescentes com essas condições em sua prática clínica (MELO, LUCENA e SARAIVA 2017).

\section{REFERÊNCIAS}

1. AUBERT, E. K. Equipamentos adaptativos para crianças com incapacidade fisica. In: TECKLIN. Fisioterapia

pediátrica. Tradução de Adriana Martins Barros Alves. 3. ed. Porto Alegre: Artmed, 2002. p 260-289.

2. Batista A. P. O processo de inclusão do deficiente físico no ensino regular das escolas municipais do perímetro urbano de Tubarão - SC (Trabalho de Conclusão de Curso). Tubarão: Universidade do Sul de Santa Catarina, 2005, p.1-69.
Santos, Lara e Folmer (2015), ressaltam ainda há necessidade de 0 profissional fisioterapeuta reconhecer e conhecer que o ambiente escolar é também um dos seus espaços de atuação, para que possa disseminar conhecimento, inicialmente, para a comunidade universitária.

\section{CONCLUSÃO}

Conclui-se que é de suma importância a interação entre professores e fisioterapeuta no processo de inclusão de crianças especiais em escolas. O fisioterapeuta possui varias habilidades que podem auxiliar na adaptação e aprendizado de alunos especiais. Porém esta relação fisioterapia e educação inclusiva ainda é pouco estudada.

Em adição, é preciso que as políticas públicas educacionais e de saúde sejam melhores definidas, no que diz respeito aos serviços prestados pelo profissional da área da saúde, em particular do fisioterapeuta, no sistema educacional, promovendo assim um ambiente acadêmico livre de práticas discriminatórias.

3. BECKUNG, E. E.; HAGBERG, G. Neuroimpairments, activity limitations, and participation restrictions in children with cerebral palsy. Developmental Medicine Child Neurology, 44(5), 309-316, 2002.

4. BRACCIALLI, L. M. P.; MANZINI, E. J.; REGANHAN, W. G. Contribuição de um programa de jogos e brincadeiras adaptados para a estimulação de habilidades motoras em alunos com deficiência física. Temas Desenvol 2004;13:37-46.

5. BRASIL. Ministério da Educação. Lei de Diretrizes e Bases da Educação 
Nacional. LDB 9.394, de 20 de dezembro de 1996.

6. CONFERENCIA MUNDIAL DE EDUCAÇÃO ESPECIAL. Declaração de Salamanca, Salamanca, 1994.

7. DE CARLO, M.M.R.; BARTALOTTI, C. C. (Org.). Terapia ocupacional no Brasil: fundamentos e perspectivas. São Paulo: Plexus. Editora, 2001.

8. DURCE, $K$. et al. A atuação do fisioterapeuta na inclusão de crianças deficientes físicas em escolas regulares: uma revisão de literatura. 0 Mundo da Saúde, São Paulo, v. 1, n. 30, p. 156-159, 2006.

9. FARIAS, N.; BUCHALLA, C. M. A classificação internacional de funcionalidade, incapacidade e saúde da organização mundial da saúde: Conceitos, usos e perspectivas. Revista Brasileira de Epidemiologia,8 (2), 187-193. 2005.

10. MACIEL, M. R. C. Portadores de deficiência a questão da inclusão social. São Paulo Perspec. V. $14 \mathrm{n}$. 2. São Paulo abr./Jun 2000.

11. MELO F. R. L. V.; CALINE. FERREIRA C. C. A. O cuidar do aluno com deficiência física na educação infantil sob a ótica das professoras. Rev. bras. educ. espec. v. 15 n.1, 2009.

12. MELO F. R. L. V.; LUCENA N. M. G.; SARAIVA L. L. O. Atuação de fisioterapeutas na inclusão de alunos com deficiência física no ensino regular. Revista Educação em Questão, Natal, v. 55 , n. 44 , p. 176199, abr.jun. 2017

13. NIEHUES, J. R.; NIEHUES, M. R. Educação Inclusiva de Crianças com Deficiência Física: Importância da Fisioterapia no Ambiente Escolar. Rev Neurocienc 2014;22(1):113-120.

14. OMOTE S. Normalização, integração, inclusão. Ponto de Vista 1999;1:4-13.

15. SANTOS, M. E. T. dos; LARA, S.; FOLMER, V. Inclusão escolar: possíveis contribuições da fisioterapia sob a óptica de professoras. Revista Educação Especial, Santa Maria, v. 28, n. 51, p. 67-82, jan./abr. 2015.

16. SARAIVA, L. L. O.; MELO, F. R. L.V. Avaliação e participação do fisioterapeuta na prescrição do mobiliário escolar utilizado por alunos com paralisia cerebral em escolas estaduais públicas da rede regular de ensino. Rev. Bras. Ed. Esp., Marília, v.17, n.2, p.245-262, maio/ago. 2011.

17. SELLERS, J. S. Professional cooperation in public school physical therapy. Physical therapy, v. 9, n. 60, p. 1159-1161, 1980.

18.SILVA, L.; MAZZOTTA, M. J. Importância da inclusão escolar na reabilitação fisioterapêutica de crianças com paralisia cerebral. Cadernos de PósGraduação em Distúrbios do Desenvolvimento, São Paulo, v.9, n.1, p.9-32, 2009.

19. TAGLIARI, C.; TRÊS, F.; OLIVEIRA, S. Análise da acessibilidade dos portadores de deficiência física nas escolas da rede pública de Passo Fundo e o papel do fisioterapeuta no ambiente escolar. Revista neurociências, v.14, n.1, p.10-14, 2006. 